\title{
Interleukin -10 - 1082A/G single nucleotide polymorphism and risk of Type 2 Diabetes Mellitus in a Southwestern population of Nigeria
}

\author{
Olubunmi G. Ayelagbe ${ }^{1 *}$, Oluwakemi O. Daodu ${ }^{1}$, Olusola A. Akanbi ${ }^{2}$, Anaelechi J. \\ Onuegbu $^{3}$, Olusola Ojurongbe ${ }^{2}$ \\ ${ }^{I}$ Department of Chemical Pathology, College of Health Sciences, Ladoke Akintola University of \\ Technology, Osogbo, Nigeria \\ ${ }^{2}$ Department of Medical Microbiology and Parasitology, College of Health Sciences, Ladoke \\ Akintola University of Technology, Osogbo, Nigeria \\ ${ }^{3}$ Department of Chemical Pathology, Nnamdi Azikiwe University, Awka, Nigeria.
}

\begin{abstract}
*Correspondence should be addressed to Ayelagbe Olubunmi G : ogayelagbe@lautech.edu.ng Received 26 January 2019; Revised 9 March 2019; Accepted 16 March 2019

(C) 2019 Ayelagbe et al. Licensee Pan African Journal of Life Sciences. This is an Open Access article distributed under the terms of the Creative commons Attribution License (https://creativecommons.org/licenses/BY/4.o), which permits unrestricted use, distribution, and reproduction in any medium, provided the original work is properly cited.
\end{abstract}

Introduction: Type 2 diabetes mellitus (T2DM) is a metabolic, multifactorial disease caused by genetic, dietary and environmental interactions with alterations in the pattern of cytokine expression. Association between interleukin (IL)-10 polymorphism and T2DM is not known in Black Africans. This study therefore investigates the relationship between IL-10 -1082A/G polymorphism and risk of T2DM in Southwest Nigeria.

Methods: 100 patients with T2DM and 105 healthy controls were enrolled. Anthropometric indices were measured and fasting blood sample was obtained from all subjects. Plasma glucose and lipid profile were estimated by standard laboratory procedures. IL-10 (-1082A/G) gene polymorphism was genotyped using Allele Refractory Mutation detection System-Polymerase Chain Reaction (ARMSPCR) technique. Odds ratio analysis (95\%CI) was used to determine association between genotype and diabetes mellitus in studied subjects.

Results: T2DM patients had the highest frequency of IL $10-1082 \mathrm{G} / \mathrm{G}$ genotype (58.3\%) while 1082AG frequency was highest (63.1\%) in non-diabetics. Non- significant associations between IL 10 1082 gene polymorphism and T2DM risk (for AG genotype: $\mathrm{OR}=0.95,95 \% \mathrm{CI}=0.19-4.2, \mathrm{p}=0.95$; for GG genotype: $\mathrm{OR}=0.49,95 \% \mathrm{CI}=0.10-2.41, \mathrm{p}=0.38$ ) were recorded. Fasting plasma glucose, 2 hours postprandial, total cholesterol and triglyceride were all significantly elevated in IL $10-1082 \mathrm{G} / \mathrm{G}$ than AG and AA genotypes in T2DM subjects $(\mathrm{p}<0.001)$. Expression of A allele was higher in controls than DM patients .

Conclusion: This case-control study did not find a significant association between IL 10-1082A/G polymorphism and T2DM; however further studies with larger sample size and IL-10 plasma level measurement will be recommended to validate this observation.

Keywords: diabetes mellitus, interleukin-10 -1082, polymorphism, Nigeria 


\section{1.o INTRODUCTION}

Type 2 diabetes mellitus (T2DM) is a chronic disease characterized by hyperglycemia as a consequence of insulin resistance or from defects in beta cell insulin production [1]. Its complications could result into increased morbidity, mortality and disability [2]. The prevalence of T2DM is on the increase with the World Health Organization (WHO) envisaging that the number of people with diabetes could be up to 500 million globally by the year 2030 [3]. In Nigeria, T2DM is one of the most challenging health problems with the estimated current prevalence of $10 \%$ [4]. The role of cytokines in pathogenesis and modification of T2DM has been reported in a previous study [2].

Interleukin 10 is an anti-inflammatory cytokine produced by $\mathrm{T}$ helper 2 cells that regulates cellular and humoral immunity [5] and can inhibit the synthesis of IL 6 [6]. IL 6 is pro-inflammatory cytokine and aggravates pathogenesis and progression of T2DM [7]. Esposito et al [8] reported that increased circulating inflammatory cytokines concentration are associated with hyperglycemia in humans. IL 10 is an immunoregulatory cytokine and has many polymorphic sites in the promoter region [7]. Genetic polymorphism of interleuILs could alter cytokine function and dysregulate their expression. It has been shown that genetic polymorphism might explain individual differences in T2DM risk and is also a determinant of incidence and severity of diabetes mellitus [9, 10, 11]. Three functional promoter single nucleotide polymorphisms (SNPs) in the IL1o locus at $-1082 \mathrm{G} / \mathrm{A}$ (rs1800896), $-819 \mathrm{~T} / \mathrm{C}$ (rs1800871) and $-592 \mathrm{~A} / \mathrm{C}$ (rs1800872) from the transcriptional start site have been confirmed to influence IL1o gene transcription [12]. Two meta-analyses found an association between the IL10 gene $-1082 \mathrm{G} / \mathrm{A}$ polymorphism and T2DM, but no association was found for $-819 \mathrm{~T} / \mathrm{C}$ or $-592 \mathrm{~A} / \mathrm{C}$ $[1,13]$. The incidence of T2DM is highly prevalent in certain ethnic populations and the influence of environmental factors has been established in populations that are genetically similar, but have different living conditions [14]. Disparities in T2DM and its complications between ethnic groups suggest that T2DM may represent a selection of particular genotypes in response to different evolutionary pressures [15].

Studies from the Caucasians [16] and Southern Indians [17] focusing on IL $10-1082 \mathrm{~A} / \mathrm{G}$ polymorphism and DM risk have produced inconsistent results. On the other hand, studies on African population are under-reported with none emanating from Nigeria. The aim of this study therefore is to investigate the contribution of IL-10 $1082 \mathrm{G} / \mathrm{A}$ SNP to the risk of developing type 2 diabetes mellitus in Southwest Nigeria.

\subsection{METHODOLOGY}

\subsection{Study Population}

100 patients attending the Internal Medicine Clinic of the University College Hospital, Ibadan, Nigeria and diagnosed with T2DM were recruited in this study. Diagnosis by the attending physician was based on the American Diabetes Association Criteria [18]. These include : fasting plasma glucose level $>126 \mathrm{mg} / \mathrm{dL}$ or 2 hours post prandial glucose level $>200 \mathrm{mg} / \mathrm{dL}$ during a $75 \mathrm{~g}$ oral glucose tolerance test and self-reported history of diabetes. 105 apparently healthy age-matched subjects participated as controls. These underwent health examinations and were confirmed not to suffer from DM [18], cardiovascular disease, pregnant nor on any lipidlowering regimen.

Patients with type $2 \mathrm{DM}$ and control subjects were interviewed at the time of recruitment in order to obtain their demographic information with the aid of questionnaire. Informed consent was sought for and obtained from all participants. This study was approved by the University of Ibadan/University College Hospital Ethical Review Committees.

\subsection{Blood Collection}

Overnight fasting blood samples ( $5 \mathrm{ml}$ ) was collected from all subjects via venipuncture of an antecubital vein. $3 \mathrm{ml}$ was dispensed into Na2-EDTA containing test tubes (final concentration $1 \mathrm{mg} / \mathrm{ml}$ ) and $2 \mathrm{ml}$ into fluoride oxalate bottles for the estimation of fasting plasma glucose. Samples were centrifuged at 100orpm for $15 \mathrm{~min}$ using Uniscope Laboratory Centrifuge (Model $5 \mathrm{~m} 112$ Surgifriend Medics, England) at room temperature to separate whole blood from plasma. Plasma harvested from EDTA tubes were used for total cholesterol, triglyceride and HDL-Cholesterol estimations.

\subsection{Anthropometric indices and plasma lipid profile}

Anthropometric indices measurement included weight in light clothing with shoes off using analogue bathroom scale, and height using standiometer. BMI was computed as weight $(\mathrm{kg}) /$ height $(\mathrm{m} 2)$. Plasma total cholesterol, triglycerides, high density lipoprotein were quantified using enzymatic kits (Boehringer Mannheim, Mannheim, Germany) and low density lipoprotein estimated as previously described [19].

\subsection{DNA extraction and PCR procedure}

DNA was isolated using Isolate II Genomic DNA kit, BIOLINE according to the manufacturer's instructions. 
Genotyping of the $\mathrm{G}$ and/or A alleles at position -1082 in IL-10 promoter region was performed by amplification refractory mutation system [ARMS] PCR as previously described [20]. Allele A was amplified with Forward Sense Primer FSP-A (5' -AAC ACT ACT AAG GCT TCT TTG GGT A-3') and allele $G$ was amplified with the primer FSP-G (5'-AAC ACT ACT AAG GCT TCT TTG GGT G -3'). Internal control primers [5' TGC CAA GTG GAG CAC CCA A 3' and 5' TGC CAA GTG GAG CAC CCA A 3'] amplifying a 700-bp fragment were included in each reaction [20]. The amplified PCR products (161bp) were separated by electrophoresis on a 1.5\% agarose gel stained with ethidium bromide and visualized under ultraviolet light. For verification of molecular analysis results, some of the samples were tested twice.

\subsection{Statistical Analysis}

Statistical analyses were performed using SASß software version 12.0. Frequencies were presented as percentages, continuous variables as mean \pm SEM. Analysis of variance was used to compare groups, $\chi^{2}$ test to examine differences in age and other variables between the subjects. The frequencies of alleles and genotypes of the whole group or subgroups of patients were compared using binary logistic regression.

Odds ratio (OR) and 95\% CI were used to assess the strength of association between IL-10 polymorphisms and the risk of T2DM under homozygote and heterozygote comparisons. The significance of the combined OR was determined, in which $\mathrm{P}<0.05$ was considered significant.

\subsection{RESULTS}

A total number of 205 individuals participated in this study. 113 (55.12\%) were females while 92 (44.87\%) were males with a mean age of $47.46 \pm 0.49 y e a r s$. Table 1 shows the biophysical and biochemical characteristics of all subjects studied. There were significant increases in fasting plasma glucose (FPG), 2 hours post prandial (2HPP), body mass index (BMI), diastolic blood pressure (DBP) , SBP- systolic blood pressure in T2DM subjects than non-diabetic controls $(\mathrm{p}<0.05)$. Considering the lipid profile, a significant increase in TG concentration $(p<0.05)$ was seen in T2DM patients compared to controls while the differences in HDL, LDL and total cholesterol were not significant $(\mathrm{P}>0.05)$. The ARMS-PCR was used to successfully used to analyzed the IL-10 -1082G/A. The two alleles of the polymorphic region of each SNP were analyzed in each patient in two different assays by ARMS-PCR (Figure 1).
Table 1: Physical and biochemical parameters in cases and control (mean \pm SEM)

\begin{tabular}{llll}
\hline Parameters & $\begin{array}{l}\text { T2DM } \\
(\mathbf{n}=\mathbf{1 0 0})\end{array}$ & $\begin{array}{l}\text { Control } \\
(\mathbf{n = 1 0 5})\end{array}$ & $\mathbf{P}$ \\
\hline Age $($ years $)$ & $49.13 \pm 1.01$ & $47.0 \pm 1.21$ & 0.180 \\
FPG(mg/dl) & $141.3 \pm 3.38$ & $84.93 \pm 1.98$ & $0.001^{*}$ \\
2HPP(mg/dl) & $272.56 \pm 4.95$ & $92.89 \pm 2.01$ & $0.001^{*}$ \\
BMI $\left(\mathrm{kg} / \mathrm{m}^{2}\right)$ & $25.27 \pm 0.51$ & $22.22 \pm 0.38$ & $0.004^{*}$ \\
TC(mg/dl) & $180.35 \pm 4.86$ & $170.20 \pm 5.12$ & 0.153 \\
TG(mg/dl) & $120.80 \pm 7.78$ & $91.38 \pm 2.62$ & $0.001^{*}$ \\
HDL-C(mg/dl) & $41.11 \pm 0.73$ & $38.93 \pm 1.09$ & 0.101 \\
LDL-C(mg/dl) & $115.62 \pm 3.89$ & $112.87 \pm 4.25$ & 0.634 \\
DBP(mmHg) & $119.16 \pm 3.34$ & $83.80 \pm 1.10$ & $0.001^{*}$ \\
SBP(mmHg) & $106.84 \pm 3.48$ & $126.78 \pm 1.19$ & $0.010^{*}$ \\
\hline
\end{tabular}

*significant@ $\mathrm{p}<0.05$

The genotype and allele frequencies of IL $10-1082$ polymorphism in diabetic patients and controls are represented in table 2. The carrier frequency of IL 10 1082 genotype in T2DM patients was 58.0, 50.4 and 6.0\% for GG, AG and AA respectively. No significant association was observed for risk of developing T2DM in GG $(\mathrm{OR}=0.49,95 \% \mathrm{CI}=0.10-2.41, \mathrm{p}>0.05)$ and $\mathrm{AG}(\mathrm{OR}=$ $0.95,95 \% \mathrm{CI}=0.19-4.2, \mathrm{p}>0.05)$ genotypes. For the nondiabetic controls, the highest frequency of $53 \%$ was recorded for AG compared to $38.0 \%$ for $\mathrm{GG}$, and $\mathrm{AA}$ (12\%) genotypes respectively.

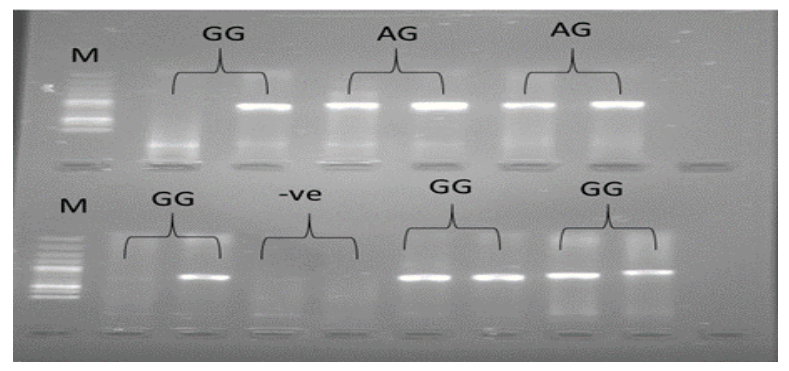

Fig 1: Fig 1 Representative genotypes of seven patients according to their IL-10 G/A polymorphism.

The percentage of AA homozygotes was generally low in the studied population, nevertheless the expression of A allele was higher in controls than DM patients. sing the Tukey multiple comparison to perform a one way ANOVA in determining the changes in biochemical parameters in T2DM based on genotype differences, GG genotype had significantly higher values of FPG, 2HPP, TC and LDL-C respectively than the AA homozygotes $(\mathrm{p}<0.01)$. Similarly, plasma $2 \mathrm{HPP}$ value increased in AG heterozygote compared to AA genotype (table 2). 
Table 2: Physical and biochemical parameters among different genotypes in T2DM subjects (mean \pm SEM)

\begin{tabular}{lllll}
\hline $\begin{array}{l}\text { Parame- } \\
\text { ters/ } \\
\text { Genotypes }\end{array}$ & $\begin{array}{l}\text { AA } \\
(\mathbf{n}=\mathbf{6})\end{array}$ & $\begin{array}{l}\text { AG } \\
(\mathbf{n}=\mathbf{3 6})\end{array}$ & $\begin{array}{l}\text { GG } \\
(\mathbf{n}=\mathbf{5 8})\end{array}$ & $\mathbf{P}$ \\
\hline Age (years) & $51.67 \pm 3.71$ & $47.42 \pm 1.77$ & $50.32 \pm 1.22$ & 0.319 \\
FPG(mg/dl) & $125.0 \pm 7.51$ & $132.3 \pm 2.42$ & $150.79 \pm 5.76$ & $0.001^{*}$ \\
$\begin{array}{l}2 \mathrm{HPP}(\mathrm{mg} / \\
\mathrm{dl})\end{array}$ & $235.5 \pm 5.29$ & $229.7 \pm 3.51$ & $258.3 \pm 8.53$ & $0.001^{*}$ \\
$\begin{array}{l}\mathrm{BMI} \\
\left(\mathrm{kg} / \mathrm{m}^{2}\right)\end{array}$ & $21.07 \pm 0.91$ & $25.98 \pm 0.85$ & $25.11 \pm 0.61$ & 0.662 \\
$\begin{array}{l}\mathrm{TC} \\
(\mathrm{mg} / \mathrm{dl})\end{array}$ & $138.3 \pm 7.54$ & $172.8 \pm 5.03$ & $191.3 \pm 7.78$ & $0.020^{*}$ \\
$\begin{array}{l}\mathrm{TG} \\
(\mathrm{mg} / \mathrm{dl})\end{array}$ & $117.6 \pm 18.26$ & $108.8 \pm 7.84$ & $131.46 \pm 13.17$ & 0.438 \\
$\begin{array}{l}\mathrm{HDL}-\mathrm{C} \\
(\mathrm{mg} / \mathrm{dl})\end{array}$ & $34.33 \pm 2.33$ & $40.13 \pm 0.83$ & $42.68 \pm 1.11$ & $0.016^{*}$ \\
$\begin{array}{l}\mathrm{LDL}-\mathrm{C} \\
(\mathrm{mg} / \mathrm{dl})\end{array}$ & $80.67 \pm 1.86$ & $110.8 \pm 4.13$ & $123.46 \pm 6.25$ & $0.026^{*}$ \\
$\begin{array}{l}\mathrm{DBP} \\
(\mathrm{mmHg})\end{array}$ & $88.0 \pm 2.52$ & $112.8 \pm 5.58$ & $103.79 \pm 4.69$ & 0.193 \\
$\begin{array}{l}\mathrm{SBP} \\
(\mathrm{mmHg})\end{array}$ & $136.33 \pm 8.41$ & $116.4 \pm 5.38$ & $119.68 \pm 4.54$ & 0.397 \\
\hline
\end{tabular}

*significant $@ \mathrm{p}<0.05$

Significant differences $(\mathrm{p}<0.001)$ in age of $\mathrm{AA}$ and $\mathrm{AG}$ genotypes as well as higher 2HPP values in GG than AG were observed in control individuals. Plasma TC and LDL $-\mathrm{C}$ also increased $(\mathrm{p}<0.001)$ in non- diabetic individuals that are homozygous carriers of A allele compared with AG and GG genotypes (Table 3).

Table 3: Physical and biochemical parameters among different genotypes in control subjects $($ mean \pm SEM)

\begin{tabular}{lllll}
\hline Parameters & AA(n=12) & AG(n=53) & GG(n=40) & P \\
\hline Age (years) & $54.25 \pm 2.46$ & $45.07 \pm 1.48$ & $49.25 \pm 2.25$ & $0.038^{*}$ \\
FPG(mg/dl) & $83.0 \pm 2.48$ & $84.55 \pm 2.68$ & $86.50 \pm 3.68$ & 0.835 \\
2HPP (mg/dl) & $90.25 \pm 3.04$ & $90.10 \pm 2.44$ & $100.50 \pm 3.96$ & $0.044^{*}$ \\
BMI (kg/m2) & $22.78 \pm 1.49$ & $22.09 \pm 0.48$ & $22.37 \pm 0.73$ & 0.859 \\
TC(mg/dl) & $166.0 \pm 18.01$ & $147.76 \pm 6.40$ & $150.83 \pm 8.16$ & $0.000^{*}$ \\
TG(mg/dl) & $96.75 \pm 4.09$ & $89.14 \pm 3.61$ & $95.0 \pm 4.27$ & 0.447 \\
HDL-C (mg/dl) & $38.25 \pm 2.25$ & $37.45 \pm 1.43$ & $42.75 \pm 1.74$ & 0.058 \\
LDL-C (mg/dl) & $108.25 \pm 15.98$ & $92.41 \pm 5.09$ & $88.83 \pm 6.78$ & $0.000^{*}$ \\
DBP(mmHg) & $84.0 \pm 2.04$ & $82.17 \pm 0.55$ & $87.67 \pm 3.75$ & 0.225 \\
SB(mmHg) & $117.50 \pm 2.02$ & $117.59 \pm 0.71$ & $114.58 \pm 4.16$ & 0.677 \\
& & & & \\
\hline
\end{tabular}

*significant @ p $<0.05$

\section{4.o Discussion}

Type 2 diabetes mellitus is a pro-inflammatory condition with evidence of cytokine polymorphism genes playing a role in modification of the risk of disease [1,21]. Interleukin 10 (IL-10), a cytokine having its gene located on chromosome 1with many polymorphic sites in the promoter region (1q31-1q32) has been implicated in the pathogenesis of T2DM [22]. A meta-analysis by Hua et al [2] observed that IL $10-1082 \mathrm{~A} / \mathrm{G}$ polymorphism contributes to an increase in susceptibility of Asian population to T2DM but this was not found in Africans. It is worth emphasizing that only one study from Africa was included in the review [2, 23]. The present case-control study therefore investigates the relationship of IL 10 $1082 \mathrm{~A} / \mathrm{G}$ polymorphism and the risk of T2DM in a population in Southwest Nigeria.

Hyperlipidaemia is common in T2DM which have been correlated with the risk of development of cardiovascular diabetic complications [24]. T2DM patients in this study demonstrated increased FPG, 2HPP, BMI, SBP and DBP values than non-diabetic controls. Data from a study involving a Chinese population also showed a significant increase in TG and BMI in diabetic subjects [25]. Allelic frequency was suggested to reflect related functional genetic variants and environmental exposure [16]. In line with this, we carried out analysis of IL $10-1082$ polymorphism in a sub-group of the participants. The carrier frequency of IL $10-1082 \mathrm{GG}$ genotype was highest in T2DM patients, also the highest mean values of FPG, 2HPP, TC and LDL-C was recorded in individuals with homozygous GG genotype although a non- significant risk of developing diabetes in GG genotypes was recorded. This observation is in agreement with a meta analysis study among Europeans [26] but at variance with other investigations carried out in a Chinese and two North African populations [10,23, 27]. Variations in these results could be attributed to genetic ethnic diversities, socioeconomic factors as well as dietary and lifestyle habits.

IL-10 -1082 AA polymorphism is associated with low IL10 production, while GA and GG are linked to intermediate and high productions, respectively [16]. A bi -allelic single nucleotide polymorphism (G/A) at position -1082 in IL-10 promoter region has been shown to influence IL-10 production in vitro and in vivo [25]. Although expression of IL -10 protein in plasma was not estimated in this work, AG genotype had the highest frequency in non-diabetic controls and did not show a significant association with risk factors for T2DM in both groups. Nevertheless, this observation does not provide enough evidence to confirm any protective role of AG genotype towards decreasing the susceptibility of our study population to type 2 diabetes. Similarly, we did not observe an association of AA genotype with diabetes mellitus but it is worthy of note that non-diabetic homozygous carriers of the A allele showed increased TC and LDL-C compared with the other genotypes. 
Data from our study revealed that IL-10 -1082GG genotype has the highest frequency but was not significantly associated with increased risk of T2DM compared to AG or AA genotypes. This case-control study reports, for the first time, a possible association between the IL-10 1082AG genotype and risk of diabetes mellitus in a Nigerian population of black African descent. A limitation of this study is the small sample size nonetheless, we believe our results could serve as a pilot for further studies. Further studies on IL-10 -592 and 819 promoter polymorphisms involving a larger population of study subjects would validate our results and provide a better understanding of the relationship between polymorphism analysis and disease susceptibility among our Nigerian population.

\section{References}

1. Mazloom Z, Yousefinejad A, Dabbaghnsmesh MH. Effect of probiotics on lipid profile, glycemic control, insulin action, oxidative stress and inflammatory markers in patients with type 2 diabetes mellitus: a clinical trial. Iran $\mathrm{J}$ Med Sci. 2013; 38(1):38-43

2. Hua Y, Shen J, Song Y, Xing Y, Ye, X. Interleukin-10 $-592 \mathrm{C} / \mathrm{A},-819 \mathrm{C} / \mathrm{T}$ and $-1082 \mathrm{~A} / \mathrm{G}$ polymorphisms with Risk of Type 2 Diabetes Mellitus: A HuGE Review and Meta-analysis. PLoS ONE 2013;. 8(6): e66568. DOI:10.1371/ oral.pone. 0066568

3. Holt RI. Diagnosis, epidemiology and pathogenesis of diabetes mellitus: an update for psychiatrists. Br Psychiatry 2004; Suppl. Apr; 47:555-63.

4. Ogbera AO, Ekpebegh C. Diabetes mellitus in Nigeria: The past, present and future. World J Diabetes 2014; 5(6): 905-911. DOI: 10.4239/wjd.v5.i6.905.

5. Pickup JC, Crook MA. Is Type 2 Diabetes Mellitus a disease of innate immune system? Diabetologica 1998; 41 (10):1241-48.

6. Arik HO, Yalcin AD, Celik B. Evaluation of soluble CD20o levels in type 2 diabetic foot and nephropathic patients: association with disease activity. Med. Sci. monit. 2015;21:1078-81

7. Mysliwska J, Zorena K, Semetkowska- Junkiewicz El. High levels of circulating IL -10 in diabetic nephropathy patients. Eur Cytokine Netw. 2005; 16(2):117-22.

8. Mahmoud AA, Sheneer A, Sayed AA. Association of IL $10(-592 \mathrm{~A} / \mathrm{C})$ gene polymorphism with its level in Type 2 diabetes mellitus with and without nephropathy. Mol. Genet. med. 2016; 10:199. Doi:10.4172/17470862.1000199.
9. Esposito K, Nappo F, Marfella R. Inflammatory cytokine concentration are acutely increased by hyperglycemia in humans. Circulation 2002; 106:2067-72.

10. Perez- Luque E, Malacara JM, Garay-Sevilla ME, Fajardo ME. Association of the TNF- $\alpha-308 \mathrm{G} / \mathrm{A}$ polymorphism with family history of type 2 diabetes mellitus in a Mexican population. Clin. Biochem. 2012; 45: 12-15.

11. Hua B, Danging J, Aitao G, Shinan Y. Association between IL 10 gene polymorphisms and risk of type 2 diabetes mellitus in a Chinese population. Int Med Res. 2014; 42,3:702-10.

12. Peng $\mathrm{X}, \mathrm{Xu} \mathrm{J}$, Wang $\mathrm{P}$, Zhou J, Guo H. Interleukin 10-1082A/G polymorphism and diabetic nephropathy: A meta-analysis. Med Sci Monit. 2015; 21: 890-894.

13. Zeng F, Yang Y, Lei H. A meta-analysis about the association between $-1082 \mathrm{G} / \mathrm{A}$ and $-819 \mathrm{C} / \mathrm{T}$ polymorphism of IL -10 gene and risk of type 2 diabetes mellitus. Hum Immunol. 2013, 74:618-26.

14. Kraine MR, Trisch RM. The role of environmental factors in insulin-dependent diabetes mellitus: an unresolved issue. Environ health perspect. 1999; 107(Suppl 5):777781.

15. Speakman JR. Thrifty genes for obesity, an attractive but flawless idea, and an alternative perspective: the 'drifty gene' hypothesis. Int J Obes. 2008; 32(11):1611-7

16. Scarpelli D, Cardellini M, Andreozzi F, Laratta E, Hribal ML, Marini MA, Tassi V, Lauro R. Variants of the interleukin-10 promoter gene are associated with obesity and insulin resistance but not type 2 diabetes in Caucasian Italian. Diabetes 2006 ; 55(5):1529-33.

17. Kolla VK, Madhavi G, Pulla RB, SrikanthBabu BM, Yashovanthi J, Valluri VL. Association of tumor necrosis factor alpha, interferon gamma and interleukin 10 gene polymorphisms with peripheral neuropathy in South Indian patients with type 2 diabetes. Cytokine 2009 Sep;47(3):173-7. doi: 10.1016/j.cyto.2009.06.007.

18. American Diabetes Association. Standards of medical care in diabetes. Diabetes care 2014; 37(51):514-580.

19. Rifai N, Warnick GR, McNamara JR, Belcher JD, Grinstead GF. Measurement of low density-lipoprotein cholesterol in serum: status report. Clin. Chem. 1992; 38: 150160.

20. Chand-Bhayal A, Krishnaveni D, Pandu-Ranga-Rao K, Prabhakar B, Vidyasagar A, Murali-Krishna B, Anita P, Jyothy A. Association of Interleukin-10 Promoter Polymorphism (-1082 G/A) and Gastric Cancer in Andhra Pradesh Population of South India. Iran J Cancer Prev. 2012. Summer; 5(3): 117-123. PMCID: PMC4294533. 
21. Kolb H, Mandrup-Poulsen T. An immune origin of type 2 diabetes? Diabetologia. 2005; 48: 1038-1050.

22. Spits H, De Waal MR. Functional characterization of human interleukin 10. Int Arch Allergy Immunol. 1992; 99:8-15.

23. Ezzidi I, Mtirauoi N, Kacem M, Mallat SG. Interleukin$10-592 \mathrm{C} / \mathrm{A},-819 \mathrm{C} / \mathrm{T}$ and $-1082 \mathrm{~A} / \mathrm{G}$ promoter variants affect the susceptibility to nephropathy in Tunisian type 2 diabetes (T2DM) patients. Clin Endocrinol (Oxf). 2009; 70 (3): 401-7.

24. O’Brien T. Hyperlipidemia and diabetes mellitus. Mayo Clin. Proc. 1998; 73:969-76
25. Matsumoto, K., Oki, A., Satoh, T., Okada, S. Interleukin-10 -1082 gene polymorphism and susceptibility to cervical cancer among Japanese women. Jpn J Clin Oncol. 2010. 40:1113-6.

26. Yin W, Sun QQ, Zhang BB. Association between interleukin-10 gene $-592 \mathrm{C} / \mathrm{A}$ polymorphism and the risk of type 2 diabetes mellitus: a meta-analysis of 4350 subjects. Cytokine. 2013; 46: 950-955.

27. Helaly MA, Hatata EZ, El-magd MA, Ibrahem EF. Association of interleukin -10 and interleukin -6 gene polymorphism with type 2 diabetes mellitus among Egyptian patients. Eur J Gen Med. 2013; 10:158-62. 